\title{
La universidad como espacio para la memoria
}

$\mathrm{R}$ ara vez las universidades incorporan en sus planes académicos estudios específicos vinculados a la memoria colectiva. Sin duda no es la única carencia. Aunque la despreocupación por este orden de saberes podría ilustrar circunstanciales descuidos, sustancialmente se convierte en un dato sensible para analizar el tipo de valores sobre los que las instituciones de enseñanza superior conciben su lugar en la sociedad. Un reiterado discurso sobre la crisis de la Universidad suele insistir en las carencias económicas que a veces parece sofocarlas. La verdad del argumento resulta indiscutible, aunque tal vez resultaría provechoso considerar que no reside allí su más acuciante problema. La Universidad, al compás de ciertos procesos que abarcan el mundo entero, ofrece precaria atención a los conocimientos alejados de prácticas inmediatamente intrumentables. Si nos atreviéramos a usar un lenguaje que no por arcaico ha dejado de ser hondamente significativo, diriamos que las cosas del espíritu han sido paulatinamente olvidadas. En realidad, tal vez se haya eclipsado el más profundo sentido de estas fundaciones que nacieron para preocuparse de aquello que interesa universalmente. No habría que descartar la hipótesis de que una reflexión que pusiera cuidado en pensar la crisis universitaria en el alejamiento de esos principios fundantes, facilitaría horizontes imprevistos y soluciones generosas.

Resulta significativo que la Universidad de Córdoba, a través del Centro de Estudios Avanzados, auspicie un Programa de Estudios sobre la Memoria que, en esta ocasión, ha sido encargado de dar forma al amplio compendio de trabajos que se ofrece en el presente número de la revista. No es pequeño el mérito de esta conducta institucional: en un sentido fuerte y crucial, la Universidad es un espacio donde la memoria ocupa un lugar cómodo y fecundo. ¿Qué otro destino podría imaginarse más alto que una vocación constante por la búsqueda del saber sin claudicaciones y que, simultáneamente, estimule el reconocimiento del pasado que lo alimenta? Sin memoria común los grupos humanos se diluyen. En ella se asienta cualquier forma de identidad que afirme la trama de nuestro vivir colectivo, de nuestro reconocimiento del otro, primer requisito para existir en común o, más intensamente, para encontrar algún sentido al vivir de cada uno. Los caminos que recorre la memoria son infinitos y alguna muestra de ello queda evidenciada en el material que se incluye en esta entrega de Estudios. Múltiples también resultan las formas en que la memoria se construye y subsiste: el arte, los testimonios, la búsqueda conciente entre residuos que a veces nos habitan calladamente; el azar: un olor que nos llega impensadamente, un rostro descubierto en el difuso 
contorno de una multitud o esa misma multitud que actualiza vivencias compartidas del pasado. A veces basta la cadencia de una voz o un dolor fugaz que se hace presente en la vibración de un instante.

Cuando entre nosotros, en la Argentina, se habla de memoria colectiva, resulta ineludible la evocación del oscuro y tormentoso período vivido hace tres décadas, caracterizado por un clima de violencia intolerante e intolerable que tuvo culminación en la dictadura impuesta durante siete años. No es casual, por lo tanto, la proporción de ensayos aquí publicados que se vinculan al tema. Nada es simple en la recordación de ese pasado durante el cual el crimen se adueñó de las calles. Las cicatrices que los recuerdan tardan en borrarse como lo muestran algunos de los artículos que se ofrecen. Es posible preguntarse, en búsqueda de enseñanzas para el vivir, si no sería deseable incorporar esas cicatrices múltiples -siempre simbólicas aunque la muerte y la ausencia sean rigurosamente sensibles- al cuerpo entero de la Nación. Vivir con esas cicatrices como parte de una memoria que aliente la posibilidad de ser mejores y no sólo mostrarlas como alegato circunstancialmente político o encubridor de verdades que nos tocan a todos. La memoria colectiva resulta impiadosa. Muestra al desnudo el presente de las sociedades que eligen recordar determinados experiencias y no otras. No hay otra posibilidad pues el olvido es implacable; la memoria, al seleccionar qué recordar, señala que la posibilidad de perder para siempre determinadas cosas resulta insoportable. La voluntad de memoria es la expresión de un estado colectivo de pensar que decide sobre el tipo de raíces en los que el presente se sostiene. Nada más próximo a la ética. Nada más urgente que instalarla en un lugar de privilegio.

Héctor Schmucler 